\title{
La doctrina foral valenciana d'època baixmedieval i la seua valoració crítica per part de misser Pere Belluga en l'Speculum principis
}

\author{
Manuel V. Febrer Romaguera (manufebrer@yahoo.es) \\ Universitat de València
}

La labor doctrinal dels juristes que existiren al regne medieval de València durant els primers segles de la implantació de l'ordenament foral no va ser al principi ni molt prolífica, ni menys encara d'una alta qualitat jurídica, sinó que, ans al contrari, es van limitar a unes poques breus monografies, algunes d'elles perdudes, les quals es van escriure des del mateix segle xIII per algun autor conegut, com ara un dels batles generals d'època de Jaume I anomenat misser Albert d'Alabanya ${ }^{1}$ qui començà a formular la més antiga doctrina foral valenciana poc després de la mateixa promulgació dels Furs de València. Altres interessants autors d'opuscles van ser, ja en el segle XIV, reputats juristes al servei de l'administració reial, com misser Guillem Jàfer el Vell en un primer moment, i més tard Gener Rabassa, tant el Pare com el Fill. Pel que fa al segle xv, destacaren el canonista fra Bonifaci Ferrer i un munt de juristes formats en les universitats europees que van redactar anotacions breus als Furs, amb les seues Notce ad foros Valentice, aprofitant les tècniques apreses dels comentadors del dret comú (Beneyto, 1935; Beneyto, 1936-1941; Guitarte, 1986). Entre tots ells, sobreïx clarament la figura del doctor en dret civil i canònic graduat a l'Estudi de Bolonya misser Pere Belluga (c. 1392-1468), que compongué diversos i voluminosos tractats, la majoria d'ells perduts, a excepció de l'interessantíssim Speculum principis, que serà l'objecte del present article en relació amb les consideracions que hi feia de la doctrina foral valenciana i els seus comentadors.

Respecte d'açò, cal plantejar-se en primer lloc si Belluga tenia a la seua biblioteca els diversos exemplars dels textos forals (els llibres de furs, actes de Cort i privilegis del Regne de València), així com els passatges doctrinals que citava; i, igualment, si posseïa les anotacions de doctrina foral que circulaven entre els juristes valencians, les Notce ad foros Valentice escrites pels legistes locals des del mateix segle XIII fins al xv que, segons les notícies que tenim, estaven arreplegades en diferents volums recopilatoris iniciats amb les notes del citat Albert d'Alabanya. Pel que fa al primer element, comparant les citacions que apareixen en l'Speculum i els volums que sabem que l'autor tenia en la seua biblioteca, s'observa que, a l'hora de referir-se a les normes forals, sembla que les hauria

\footnotetext{
${ }^{1}$ Ben probablement no era originari de Catalunya ni d'Occitània, puix l'existència d'una vila piemontesa anomenada Lavagna, de la qual sabem que a mitjan segle xiII era comte el noble Hugo Fieschi, ni més ni menys que germà del papa canonista Innocenci IV (Sinibaldo Fieschi), indueix a pensar que el seu origen familiar es trobara allà, amb el nom real d'Alberto da Lavagna.
} 
pogut consultar mitjançant els diversos exemplars de furs, actes de Cort i privilegis del regne que, en efecte, posseïa. No passa igual, però, quan es referia al segon element, a les opinions dels anomenats furistes, ja que, segons l'inventari de la biblioteca elaborat després de la defunció de Belluga, no consta clarament que posseïra cap exemplar de les Notce ad foros Valentia. No obstant això, malgrat la significativa mancança de referències en la biblioteca, sembla que el jurista coneixia suficientment la doctrina foral valenciana, com clarament demostra el fet que la citara nombroses vegades, tant esmentant directament algun autor com citant-ne d'altres de manera genèrica, als quals anomenava «foristæ» 0 «foristas» (Belluga, en premsa: rúb. XI, cap. IV; rúb. XLVII, cap. I; rúb. XLVII, cap. I).

\section{La malfiança envers els furistes valencians}

La doctrina foral valenciana tenia una presència reduïda en l'Speculum principis, que contrasta clarament amb l'abundantíssima doctrina procedent dels molts tractadistes del dret civil i canònic d'origen italià i francés que Belluga citava a cada pas. L'exigu tractament que mereixia la doctrina foral valenciana al llarg de l'obra es troba demostrat si analitzem les poques i desconsiderades referències als autors valencians que hi apareixien. Entre elles, es trobaven citacions a opinions puntuals de Guillem Jàfer el Vell, Gener Rabassa el Fill i Joan Mercader, que es completaven amb inconcretes i genèriques opinions de furistes que ni tan sols es precisaven esmentant-ne els noms dels autors. A pesar que Belluga solia deixar sense tractar els aspectes tècnics o metodològics que revestia la jurisprudència de caràcter bartolista, la qual predominava a la València d'aleshores, sovint no volia deixar sense crítica la seua posició revisionista de molts aspectes dels anotadors forals, adoptant interpretacions que solien compartir els autors humanistes contemporanis i fent objecte de crítiques regeneracionistes les solucions jurídiques que presentaven els anteriors juristes del ius commune. Per aquesta raó, no podia prescindir d'efectuar crítiques puntuals a la doctrina foral valenciana, ja que donaven a entendre la seua innovadora posició humanista, i no resulta estrany comprovar que freqüentment indicava deficiències en les interpretacions donades pels furistes al sentit de determinats furs.

Evidentment, la formació dels juristes escolàstics valencians de l'època, que Belluga qualificava de furistes, li devia semblar inadequada o antiquada, malgrat estar apresa de grans juristes de les escoles italianes i franceses del dret comú, dels quals ell mateix havia begut els fonaments de la seua ciència (Calasso, 1954; Piano Mortari, 1976; Carpintero, 1977; Carpintero, 1980; Viehweg, 1980). Però la circumstància d'haver assumit els plantejaments humanistes feia que Belluga orientara les posicions que mostrava enfrontant-se sovint amb les mantingudes pels furistes, tot i presentar tècniques d'anàlisi i metodologia similars, com era lògic per la seua comuna formació jurídica bolonyesa. La pretensió d'efectuar una sistematitzadora justificació de les seues interpretacions, depurant les tesis o hipòtesis en clau dialèctica, opinió a opinió, dissensió a dissensió, es dirigia a conservar i perpetuar les riques formes rebudes de la ciència jurídica escolàstica, centrant-se sols a formular una crítica interpretativa d'opinions puntuals dels furistes valencians, sense diferenciar excessivament quan se significaven per mantindre's fidels o divergents respecte a la més generalitzada doctrina del dret comú (Bellomo, 1999: 217-249). 
Atenent aquesta actitud - a l'estil d'algunes de les crítiques que els humanistes formulaven contra els autors de l'escolàstica jurídica-, Belluga solia llançar-se a formular dures invectives contra els furistes valencians desqualificant la seua perícia jurídica quan s'allunyaven de la interpretació literal que pensava que mereixien algunes disposicions forals. Malgrat això, no podia reconéixer que els furistes tingueren justificada la seua pretensió de ser seguidors fidels dels glossadors i comentaristes del dret comú, intentant aclarir que, no poques vegades, s'allunyaven d'ells. Sobretot quan pretenien interpretar correctament les normes romanes i els furs, defensant que les primeres eren de directa aplicació en juí, com si foren furs, i oblidant que aquesta possibilitat, a més d'estar en desacord amb les prescripcions forals, estava expressament prohibida, tant als advocats com als jutges, quan respectivament procedien a formular al-legacions i a resoldre les qüestions conforme a aquelles. Per això, Belluga considerava sorprenent que els furistes adoptaren posicions contradictòries quan defensaven que tant el dret foral com el procediment que aquest preveia eren ius commune (Belluga, en premsa: rúb. XxxII, cap. I).

No obstant això, Belluga no sempre mantenia aquella posició, perquè no poques vegades criticava els furistes precisament per defensar una opinió justament contrària a la seua anterior crítica, per exemple quan considerava que la doctrina foral s'equivocava quan defensava que resultava impossible al·legar jurisdiccionalment allò que preveia el dret comú, en el concret cas que suposava la conveniència de seguir-lo en la qüestió referida al destí que, en l'opinió que donaven els furistes, havien de seguir els béns dels vassalls que per obligacions dels seus senyors feudals haurien de patir les execucions que sobrevingueren sobre els seus patrimonis privats (Belluga, en premsa: rúb. XXXII, cap. II). Encara que resultara incongruent la posició que Belluga mantenia sobre aquesta qüestió, només per contradir les opinions que mantenien els furistes locals, sembla que no tenia inconvenient a dissentir amb les posicions que havien mantingut reputats doctors del dret comú, que ocasionalment coincidien amb els furistes valencians tot just en considerar que els béns dels vassalls no haurien de ser executables per deutes dels seus senyors, admetent solucions que prescindien de les normes romanes que preveien la possibilitat que els vassalls foren executats solidàriament per deutes senyorials (Belluga, en premsa: rúb. XXXII, cap. II).

En efecte, després de referir-se amb respectuós dissentiment a les opinions coincidents que mantenien tant Cino da Pistoia com el seu mateix mestre Giovanni da Imola respecte al tema en qüestió, en contra de la tradicional previsió contemplada pel dret comú (Belluga, en premsa: rúb. XXXII, cap. II), ${ }^{2}$ no podia ocultar que no li mereixia idèntic respecte la posició semblant que defensaven alguns furistes locals, tot seguint la particular pràctica progressiva de l'Estil de la Cort de la Governació del Regne, la qual irrespectuosament pensava que, per no seguir els criteris del dret comú, mereixia ser qualificada de pròpia de juristes «bestiales» (Belluga, en premsa: rúb. XxxII, cap. II). Encara que altres vegades es mostrara menys despectiu respecte a la doctrina foral valenciana, no desaprofitava cap oportunitat

\footnotetext{
${ }^{2}$ El passatge en què Belluga dissentia de Cino i Giovanni da Imola deia: «Dicens [Iohannes de Ymola], quod bona vassallorum non sunt domini sicut neque bona singulorum sunt imperatore, et sic in illis, de iure nequit fieri executio. Et ideo aliqui foristi in foro: Can algú, rubrica, de pignoribus; dicunt illud esse preter ius; et sic approbari per notata per Cynus in lege prima, C. que sit longa consuetudo. Sed istud est falsum, immo expresse contra ius; nam licet cum iudex superior est in fatiqua iustitiæ possit sua gens parere et executari».
} 
per a deixar constància de la falta de confiança que li mereixien els criteris d'aquells autors, evidenciant-ho quan puntualment es lamentava que cap dels anteriors juristes, ni els doctors del regne, ni menys encara els furistes coetanis, mai hagueren tractat, i ni tan sols entés, alguns dels seus arguments (Belluga, en premsa: rúb. XLI, cap. III). ${ }^{3}$

Semblant desconsideració demostrava enfront de les posicions jurídiques que defensaven certs advocats locals quan, per divergir de les seues opinions, no sols els tractava com a «cavilosi advocati» (Belluga, en premsa: rúb. XI, cap. i), sinó més encara de «cavillantes et perfidi advocati» (Belluga, en premsa: rúb. XLI, cap. XXVIII), mostrant-se partidari d'un tipus de crítica humanista contrària a les habituals disquisicions juridicodialèctiques que després serien especial motiu de preocupació en humanistes com Joan Lluís Vives (Nero, 1992: 183) - quan per exemple censurava la mania dels advocats d'embolicar-se en «stultis ac ineptis cavillis». En una altra citació no ocultava el disgust que li havia produït la circumstància que cap dels doctors de la ciutat haguera seguit l'al·legació legal que ell havia mantingut en una ocasió per a resoldre una qüestió que se li havia presentat en qualitat de jutge arbitral (Belluga, en premsa: rúb. XLI, cap. XXIV) ${ }^{4}$. Més encara, es lamentava que els furistes locals mai hagueren parlat del dret d'amortització fins que ell per primera vegada l'havia estudiat, segons creia (Belluga, en premsa: rúb. xiv) ${ }^{5}$, quasi atribuint-se el seu descobriment, sense massa raó, ${ }^{6}$ per pensar que cap altre jurista ni havia arribat a conéixer que existia, ni menys haver-lo fet objecte d'estudi. ${ }^{7}$

En una línia despectiva semblant, no deixava de mostrar-se contrari a l'opinió que mantenia un antic furista, a qui no citava, ${ }^{8}$ la qual deia haver-li escoltat $-\ll$ sic audivit ab aliquo doctore antiquo»- declarant-se favorable al fet que els posseïdors del mixt imperi pogueren rebre les seguretats de pau i treva, sota sagrament i homenatge, tenint facultat per a imposar i cobrar als qui els trencaren la mateixa pena prevista per als traïdors. Al-legant les opinions de Bartolo i Baldo, deia que aquelles eren competències exclusives dels posseïdors del mer imperi, coincidint en això amb el criteri que encertadament, en opinió seua, sovint mantenia el procurador fiscal del regne Pere d'Anglesola, el qual pensava que els justícies que tenien jurisdicció civil no podien exercir competències que havien de considerar-se com a sols pertanyents als posseïdors del mer imperi (Belluga, en premsa: rúb. XXIV, cap. vI). ${ }^{9}$

\footnotetext{
${ }^{3}$ La cita deia: «Et nota predicta, quia neque forista neque aliquis doctor in regno, unquam hanc materiam tibi declararunt, et multi eam non intelligebant, que illam lingua materna potuerunt predicare».

${ }^{4}$ El text indicava: «Et istius oppinionis erant fere omnes doctores in civitate me existente iudice, videlicet quod lege quicumque allegata, haberet locum, etiam quod una prestatione esset facta solutio trium pensionum. Sed non obstante hoc in contrarium pronunciavi».

${ }^{5}$ La cita deia: «Et svper materia amortizationvm, que materia a iuristis ignorata, a foristis omissa, a Deo querenda est doctrina».

${ }^{6}$ Havien parlat de la matèria tant un jurista occità del segle XIv de l'escola d'Orleans, Pèire Jacme d'Orlhac († c. 1351), com el català del segle xv Jaume Callís (Jacme, 1501; Callís, 1556).

${ }^{7}$ L'interès per la matèria havia arrelat especialment en terres franceses (Sautel, 1965) i més tard ho va fer en les terres hispàniques (Clavero, 1988).

${ }^{8}$ Possiblement, es referira a algun escrit de Guillem Jàfer, tot i no ser un autor coetani de Belluga (Jàfer, 1936).

${ }^{9}$ En concret, deia: «Et hoc est quod dicit cotidie noster fisci procurator, in regno Valentie, Petrus de Angularia, quod iustitie civilium iurisditionum, tales paces nequeunt recipere, sic audivit ab aliquo doctore antiquo. Videtur ergo quod bene dicat procurator regius per predicta. Pro quo etiam facit, quia hec essecuramenta, et paces, et similia, sunt de mero imperio».
} 


\section{Les crítiques a Jàfer, Rabassa i Mercader}

A pesar de les referides inconcrecions, no deixava de citar en algunes ocasions reputats autors furistes, com per exemple el més antic dels juristes de la família Jàfer, anomenat misser Guillem Jàfer el Vell, que havia viscut en la primera meitat del segle xIv. Una primera vegada el trobem puntualment citat, no per tal de coincidir amb el seu criteri d'autoritat, sinó per a rectificar l'opinió que havia defensat amb motiu d'una nota que havia formulat al fur Si.ls cavallers, de la rúbrica "De feudis"; en concret, s'hi havia referit al fet que el noble o baró podien posseir jurisdicció alta i baixa exclusiva en la seua baronia sense tindre en compte que el rei sempre hi conservava la superior jurisdicció que li corresponia com a monarca i senyor de la protecció general, la qual li pertanyia tant en els territoris que posseïa a títol particular com en la totalitat de les terres del regne (Belluga, en premsa: rúb. XXIV, cap. vi; Notae ad foros, Llibre IX, rúb. XXI). ${ }^{10}$

En una altra ocasió tornava a censurar les opinions de Jàfer formulades en comentar el mateix fur, quan tractava la possibilitat que tenia el príncep d'advocar o conéixer aquelles causes en què, tot i ser de competència d'un baró posseïdor de la corresponent jurisdicció, es constatava que s'havia denegat a un vassall l'aplicació de la justícia a la qual tenia dret (Belluga, en premsa: rúb. xxIII, cap. II; Notae ad foros, Llibre IX, rúb. XxI). ${ }^{11}$ A pesar que aparentment no ho deixara aclarit, tant en el cas d'una citació com en el de l'altra atribuïda a Jàfer, sembla que Belluga, més que a les seues breus intervencions en les Notce ad foros Valentice, voldria referir-se més prompte a les extenses opinions que havia formulat en el seu tractat sobre els furs nous d'Alfons el Benigne (Jàfer, 1936).

Així mateix, puntualment també es referia a algunes concretes opinions sobre la interpretació d'uns furs fetes pel conegut furista misser Gener Rabassa el Fill (†1412), tractades segurament en els comentaris recollits en les Notce ad foros Valentice, fent referència a la forma que el jutge podia rebre testimonis en juí, tant d'ofici, per denúncia o per via d'inquisició. Belluga pensava que l'opinió d'aquell autor, malgrat seguir la d'altres furistes i respectant el seu descans en pau (com a difunt des de 1412), mereixia corregir-se: «salva eius determinatione et pace, credo eum non bene dixisse» (Belluga, en premsa: rúb. xxxIII, cap. Xv). ${ }^{12}$

Finalment, també feia referència a unes contradictòries al-legacions jurídiques formulades pel conegut doctor en drets i furista misser Joan Mercader ( $† 1443)$, batle general del regne i

\footnotetext{
${ }^{10}$ L'argument que Belluga formulava contra Jàfer deia: «Et ad hoc bene facit forus, Si.ls cavalers, de feudis. Et quod ibi notatur per Guillermum Iaffer, qui dicit quod licet nobilis vel baro habeat iurisditionem altam et baxam in sua baronia, tamen non est verum quod dominus rex nullam iurisditionem habeat in eis, cum ipse in omnibus regnis, et terris suis sit monarcha et dominus quo ad iurisditionem generalem et protectionem».

${ }^{11}$ La citació de Belluga literalment deia: «Sed in hoc casu princeps utitur evocationibus, et milites et barones tacent, taceant, ergo, quoniam et tacebo, et princeps querit ex consuetudine et possessione, maxime, quia facta contradictione obtinetur in contradictorio iuditio pro principe, et sic est modus validus consuetudinis introducentis, ut in capitulo abbate Sancti Silvani, de verborum significatione; et quod ibi notatur; et communiter pro hac parte allegatur forus, "Si.ls cavallers, de feudis"; et quod ibi notatur per Guillermum Iafer».

${ }^{12}$ Les citacions referides a Rabassa deien: «Item istud iam fortius procedit de foro, de quo solum post publicationem datur facultas obitiendi et sententiandi in negotio ab ipso foro: En fer inquisitions, et in foro: La Cort, rubrica, De la Cort; ubi tenent aliqui foristæ, ut habeo per dominum Generium Rabaça. [...] Nam multi sunt casus de foro, in quibus si procedat infamia, et privata sit facta denunciatio, etiam aliquando sine illa iudex inquirit, et illam privatus non prosequitur, et illam iudex fisco instante prosequitur ex officio, ut satis ut satis late diximus, merito iudex ex officio tali casu, tam ad offensam, quam ad deffensam, potest testes recipere».
} 
autor igualment de diversos comentaris inclosos en les Notce ad foros Valentice, quan amb ocasió d'una polèmica qüestió sorgida en les Corts iniciades en 1437, tot assumint la defensa dels arguments de la Corona, havia efectuat al·legacions que s'oposaven a la interpretació de Belluga, qui pretenia donar suport a les posicions del braç reial. En concret, aquests exigien que, prèviament a la votació en Corts del subsidi i dels furs, el rei complira l'obligació foral de resoldre els greuges comesos pels alts oficials reials, per via del nomenament dels preceptius inquisidors d'oficials (Belluga, en premsa: rúb. XXXV, cap. VII).

\section{Una visió crítica lligada al nou humanisme}

En definitiva, el jurista Pere Belluga (c. 1392-1468) es mostrava pràcticament sempre crític, en qualsevol circumstància, amb els furistes i la doctrina foral valenciana que s'havia anat conformant des de la creació del Regne de València i la promulgació dels furs valencians en 1238. El motiu, probablement a banda de la particular personalitat d'aquell doctor en lleis, l'hem de trobar en la seua formació i la seua postura de caràcter humanista, vinculades als nous corrents culturals i jurídics que s'irradiaven des de la península Itàlica a començaments del segle XV i que va fer seus al llarg de la seua carrera, com mostra clarament l'anàlisi global i sectorial de la seua principal obra conservada, l'Speculum principis.

\section{BIBLIOGRAFIA}

Belluga, P. (en premsa): Speculum principis, ed. Manuel Vicent Febrer Romaguera.

Beneyto, J. (1935): Per un índex d'escriptors "Super foris Regni Valentice", València, Vives Mora.

- (1936-1941): «Sobre las glosas del Código de Valencia», Anuario de Historia del Derecho Español, $13,150-165$.

Bellomo, M. (1999): La Europa del derecho común, Roma, Il Cigno Galileo Galilei.

CAlasso, F. (1954): Medioevo del diritto. I. Le fonti, Milà, A. Giuffré.

CALlís, J. (1556): Margarita fisci, Barcelona, Joan Guardiola.

CARpintero, F. (1977): «"Mos italicus", “mos gallicus” y el humanismo racionalista. Una contribución a la historia de la metodología jurídica», Ius Commune, 6, 108-171

- (1980): «En torno al método de los juristas medievales», Anuario de Historia del Derecho Español, $52,617-642$.

Clavero, B. (1988): «“Amortizatio”. Ilusión de la palabra», Quaderni fiorentini per la storia del pensiero giuridico moderno, 17, 319-358.

Guitarte, V. (1986): El pensamiento jurídico valenciano del siglo XIII al XIX. Aportaciones a su historia, Castelló de la Plana, Fundación Balaguer Gonel, 1986.

JACME, P. (1501): Aurea practica congruis et necessariis libellis ordine dicenti collocatis, Lyon, Jacques Sacon.

JÀFer, G. (1936): Declaracions fetes de duptes sobre los Furs nous, ed. J. Beneyto: «Un Opúsculo jurídico de Jaffer», Boletín de la Sociedad Castellonense de Cultura, XVII, 69-81.

Nero, V. (1992): «Pedagogia e psicologia nel pensiero di Vives», Ioannis Ludovici Vivis. Opera omnia. $I$, València, Institució Alfons el Magnànim.

Nota ad foros Valentiae, Biblioteca Històrica de la Universitat de València, Ms. 205 i 208.

Piano Mortari, V. (1976): Dogmatica e interpretazione, Nàpols, Jovene.

SAutel, G. (1965): «Note sur la formation du droit royal d'amortissemente (XIIIe.-XIVe. siècles)», Études d'Histoire du Droit Canonique dédiées a Gabriel Le Bras, París, Sirey, I, 689-704.

VIeHWEg, T. (2007): Tópica y jurisprudencia, Madrid, Civitas. 


\section{BIONOTA}

\section{Manuel V. Febrer Romaguera}

Doctor en Història Medieval i en Dret Civil, és catedràtic de Geografia i Història de secundària, on imparteix docència. És autor d'un centenar d'articles i d'una vintena de monografies sobre la història dels mudèjars, la història de la Universitat de València, la història local i comarcal de la Ribera i la història del dret i les institucions forals valencianes. Ha rebut diversos guardons, com el Premi d'Investigació Ciutat de Silla o el de Picanya, i és cronista oficial de la vila d'Alcàsser. 